\title{
Asymmetric Electrodes Constructed with PAN-Based Activated Carbon Fiber in Capacitive Deionization
}

\author{
Mingzhe Li, Yingzhi Chen, Zheng-Hong Huang, and Feiyu Kang \\ Key Laboratory of Advanced Materials (MOE), School of Materials Science and Engineering, Tsinghua University, \\ Beijing 100084, China \\ Correspondence should be addressed to Zheng-Hong Huang; zhhuang@mail.tsinghua.edu.cn
}

Received 4 December 2013; Accepted 8 February 2014; Published 11 March 2014

Academic Editor: Jian Lin

Copyright (C) 2014 Mingzhe Li et al. This is an open access article distributed under the Creative Commons Attribution License, which permits unrestricted use, distribution, and reproduction in any medium, provided the original work is properly cited.

Capacitive deionization (CDI) method has drawn much attention for its low energy consumption, low pollution, and convenient manipulation. Activated carbon fibers (ACFs) possess high adsorption ability and can be used as CDI electrode material. Herein, two kinds of PAN-based ACFs with different specific surface area (SSA) were used for the CDI electrodes. The CDI performance was investigated; especially asymmetric electrodes' effect was evaluated. The results demonstrated that PAN-based ACFs showed a high electrosorption rate (complete electrosorption in less than half an hour) and moderate electrosorption capacity (up to $0.2 \mathrm{mmol} / \mathrm{g}$ ). CDI experiments with asymmetric electrodes displayed a variation in electrosorption capacity between forward voltage and reverse voltage. It can be attributed to the electrical double layer (EDL) overlap effect and inner pore potential; thus the ions with smaller hydrated ionic radius can be adsorbed more easily.

\section{Introduction}

Water scarcity has become an increasing concern on the earth. Fresh water accounts for only $0.007 \%$ of the global water resources. Yet, such a small amount of water has been unconscionably exploited and overused by continuously increasing population [1]. On the other hand, sea water and brackish water constitute nearly $97 \%$ of the water resources, but these kinds of water cannot be used directly. Therefore water desalination plays a significant role in reduction or even elimination of water crisis [2]. Capacitive deionization (CDI) is a promising method of water desalination. The concept was first brought forward by Caudle from America in the 1960s [3]. Then, Johnson made great contribution on electrosorption and electrolysis adsorption. In the late twentieth century, a brand new method: Flow-Through Capacitor (FTC) for electrosorption deionization using the capacitive character theory was proposed. CDI has the advantages of convenience, low energy consumption, and absence of secondary pollutant [4]. The mechanism of CDI involves application of an electric field between two electrodes to force ionic species toward oppositely charged electrodes. The ions are held within the electrical double layer (EDL) formed near the electrode surfaces $[5,6]$. A part of these ions belongs to nonelectrosorption, namely, the physisorption or chemisorption; the other part belongs to electroadsorption, which is reversible. When the adsorption has reached an equilibrium condition, electrodes can be regenerated with ease by reversing the power supply or to short the circuit while adsorbed ions are released.

CDI's performance relies on its adsorbing efficiency [7], which is mainly influenced by electrode materials, apart from external conditions such as solution's concentration. If CDI's efficiency can reach $85 \%$ or more, then CDI could be a real rival for reverse osmosis and distillation. In fact, scientists have successfully made carbon electrode with cyclic efficiency of over $90 \%$ [8]. Many kinds of carbon materials have been used and tested as CDI's electrode, and the high CDI performance usually depends on the physical and structural properties of the electrode materials such as specific surface, conductivity, and pore size distribution. Relatively high specific surface area (SSA) and better conductivity contribute to a better adsorption capacity $[9,10]$. Graphene or carbon nanotubes (CNT) [11-13] have to be attached to other supporting materials with the assistance of additives [14-16]. While self-supporting materials like carbon aerogel 


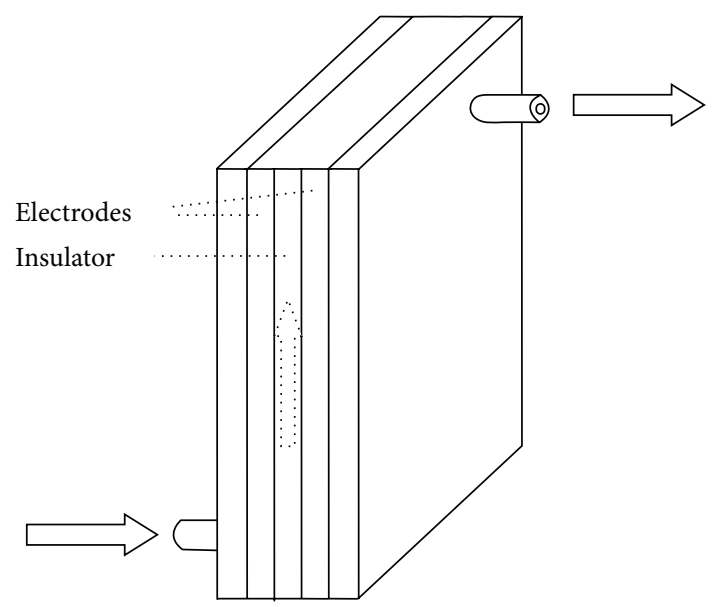

FIGURE 1: Schematic of CDI cell with PAN-based ACFs electrodes.

$[17,18]$ and activated carbon fiber (ACF) [19] encourage better CDI behavior by avoiding the complex fabrication [20]. Apart from the material type of the electrodes', the geometric dimensioning could also affect CDI performance. Recently, Porada et al. [21] reported the effect of electrode thickness variation on $\mathrm{CDI}$, in which they used different layers of anode and cathode made of chemically unmodified porous carbon particles. By doubling and tripling one electrode but not the other, they obtained increasing salt adsorption. Their work revealed that EDL structure is independent of the sign of the electronic charge.

In the present work, we exploited activated carbon fibers (ACFs) electrodes with different specific surfaces and studied the influence of electrodes asymmetry's on CDI performance. Electrodes with size asymmetry and material asymmetry were used in CDI process and electroadsorption performances were analyzed. Different from Porada's research, we used electrodes with various geometric sizes other than thickness and evaluated the CDI performance.

\section{Experiment}

2.1. Material. The PAN-based ACFs used in the experiments were kindly provided by Professor Tse-Hao Ko from Feng Chia University, Taiwan. The ACFs were produced by the process of stabilization, precarbonization, carbonization, and surface treatment $[22,23]$. The ACF samples were designated as P7 and P10 according to their Brunauer-Emmett-Teller (BET) surface areas of 700 and $1000 \mathrm{~m}^{2} / \mathrm{g}$.

2.2. Characterization. The morphologies of the PAN-based ACFs were measured by a LEO-1530 scanning electron microscopy (SEM). The Brunauer-Emmett-Teller (BET) surface areas and pore structure parameters were characterized by $\mathrm{N}_{2}$ sorption method at $77 \mathrm{k}$.

2.3. CDI Configuration. A typical configuration (Figure 1) of the flow-through CDI cell usually comprises two parallel electrodes with an in-between insulating spacer of $5.5 * 5 \mathrm{~cm}^{2}$,

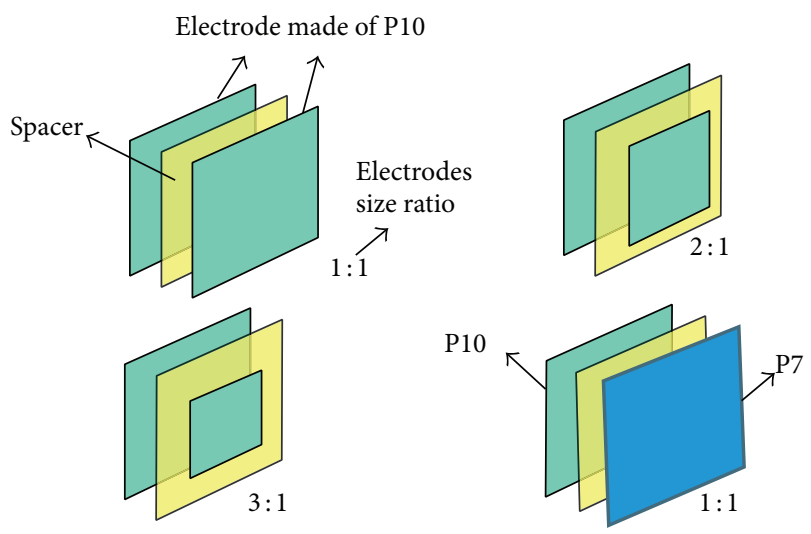

FIGURE 2: Schematic of asymmetric electrodes.

just as depicted in our previous work [3]. The electrode was made up of PAN-based ACFs cloth. In the CDI process, a $\mathrm{NaCl}$ aqueous solution was continuously pumped into CDI cell at a rate of $6 \mathrm{~mL} / \mathrm{min}$ from a peristaltic pump. All the experiments were operated in a thermostatic chamber under $20^{\circ} \mathrm{C}$ with a cell voltage of $1.2 \mathrm{~V}$, just a little lower than the water electrolysis potential. The ion adsorption behavior is reflected by the change of solution's conductivity, which was monitored online by a conductivity meter (type $308 \mathrm{~A}$, Leici Co.) with $10 \mathrm{~s}$ interval.

2.4. CDI Performance Evaluation. To study the influence of electrode symmetry on CDI performance, asymmetric electrodes (Figure 2) were designed to treat $\mathrm{NaCl}$ aqueous solution.

(1) Size asymmetry: both P10 electrodes with a tailored geometric proportion of $1: 1,2: 1$ and $3: 1$ were constructed to study the CDI behavior, with one electrode remaining the same size while the other is smaller and smaller.

(2) Material asymmetry: two same sized electrodes with different material of P7 and P10 were constructed to study the CDI behavior.

\section{Results and Discussion}

3.1. Structural Analysis. The SEM image of the two PANbased ACFs (Figure 3) shows that the P7 and P10 cloth have smooth, cross-linked fibers with diameter of 8 and $5 \mu \mathrm{m}$, respectively. $\mathrm{N}_{2}$ adsorption results (Figure 4) indicate that both ACFs are microporous materials. Detailed pore parameters are listed in Table 1. P10 demonstrates higher SSA and bigger average pore width and volume than P7.

3.2. Capacitive Deionization Performance with Symmetric Electrodes. To evaluate the PAN-based ACFs' CDI performances, $\mathrm{NaCl}$ aqueous solutions with different concentration were fed into the CDI cell with P7 and P10 symmetrical electrodes, respectively. Before each experiment, electrodes 


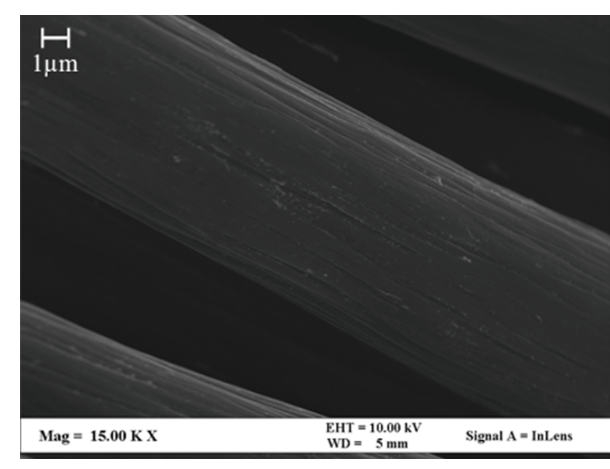

(a)

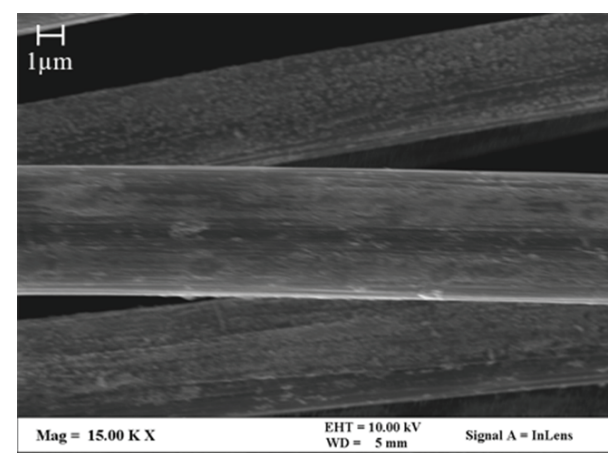

(b)

FIgURE 3: SEM image of P7 (a) and P10 (b).

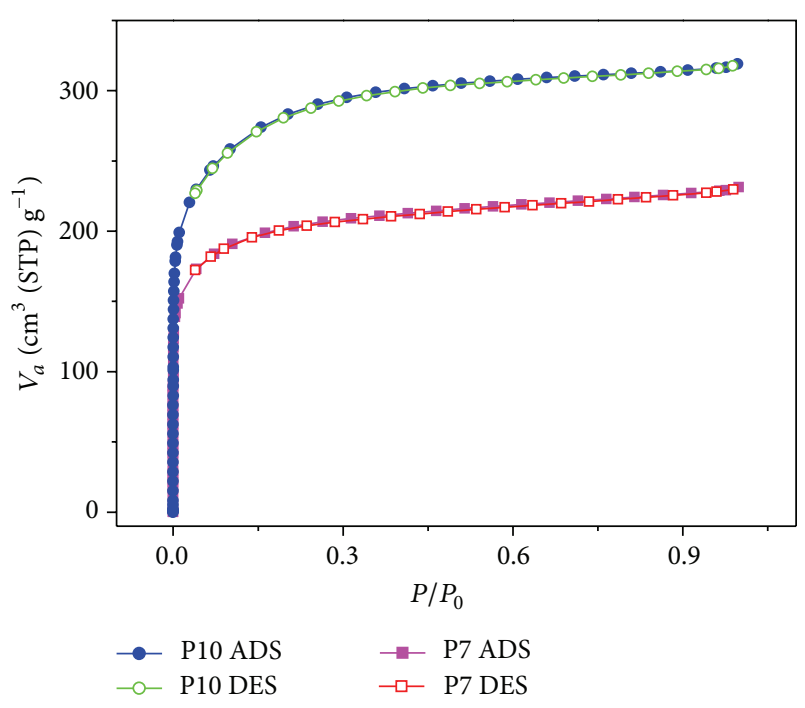

Figure 4: $\mathrm{N}_{2}$ adsorption/desorption isotherms of P7 and P10.

were washed by pure water until no salt remained and then dried with nitrogen.

Total adsorption of ions consists of two parts, nonelectrosorption and electrosorption. At first when the $\mathrm{NaCl}$ aqueous solution was input into the CDI cell, solution's concentration dropped because of physical adsorption or chemical adsorption. Nonelectrosorption is irreversible. After the nonelectrosorption reached equilibrium, electric field was applied, and the electrosorption process started (Figure 5). Here, electrosorption is reversible. After electrosorption reached an equilibrium state, electric field was reversed manually and ions' desorption proceeded, in which the electrodes were regenerated. If the reversed electric field was applied continually, electrodes would begin to adsorb ions in solution again, thus beginning a new cycle. It can also be seen that PAN-based ACFs electrodes had a quite fast adsorption rate. It only takes less than half an hour for PANbased ACFs to complete most of the electrosorption process, which would take more than an hour for CNT sponges (100 min) [3], pitch-based ACF (65 min) [24], mesoporous activated carbon (100 $\mathrm{min}$ ) [9], and some other carbon
TABLE 1: PAN-based ACFs' pore structure parameters.

\begin{tabular}{lccc}
\hline Sample & $\begin{array}{c}\text { BET SSA } \\
\left(\mathrm{m}^{2} / \mathrm{g}\right)\end{array}$ & $\begin{array}{r}\text { Pore volume } \\
(\mathrm{cc} / \mathrm{g})\end{array}$ & $\begin{array}{c}\text { Average pore } \\
\text { width }(\mathrm{nm})\end{array}$ \\
\hline P7 & 754 & 0.36 & 1.9 \\
P10 & 1000 & 0.49 & 2.0 \\
\hline
\end{tabular}

materials under the same conditions. This high adsorption rate contributes to a high adsorption efficiency of PAN-based ACFs. However, it is shown that PAN-based ACF possesses a lower electrosorption capacity in comparison with pitchbased ACF [24] because its higher nonelectrosorption has a negative effect.

The electrosorption isotherms of PAN-based ACFs were obtained by altering the feeding concentration (Figure 6). It shows that P10 has a higher adsorption capacity at higher equilibrium concentration. This is because under low solution concentration, only a few ions contact and impact pores of electrodes' surface, so adsorption and desorption reach equilibrium state at low electrosorption capacity; while under high solution concentration, more ions contact and interact with surface's pores and more surface area is effective in electrosorption, so electrosorption reach equilibrium at higher capacity. We can correlate the experiments data fit with the Langmuir model and Freundlich model, shown in (1) [25]

$$
\begin{gathered}
Q=\frac{Q_{m} K_{L} C_{e}}{1+K_{L} C_{e}}, \\
Q=k_{f} \cdot C_{e}^{1 / n} .
\end{gathered}
$$

$Q_{m}$ is the maximum adsorption capacity $(\mathrm{mmol} / \mathrm{g}) . C_{e}$ is the equilibrium concentration $(\mathrm{mmol} / \mathrm{L})$. $Q$ is the specific adsorption capacity $(\mathrm{mmol} / \mathrm{g})$ while solution's concentration is $C_{e} . K_{L}$ is Langmuir constant, $k_{f}$ and $n$ are Freundlich constants.

Both Langmuir model and Freundlich model fit the data well with P7's correlation coefficient being around 0.99 and P10's being around 0.83 . This suggests a monolayer adsorption of ions on the electrodes' surface under the experimental concentrations [26]. The theoretic capability to adsorb $\mathrm{NaCl}, Q_{m}$, presents an adsorption capacity of over 


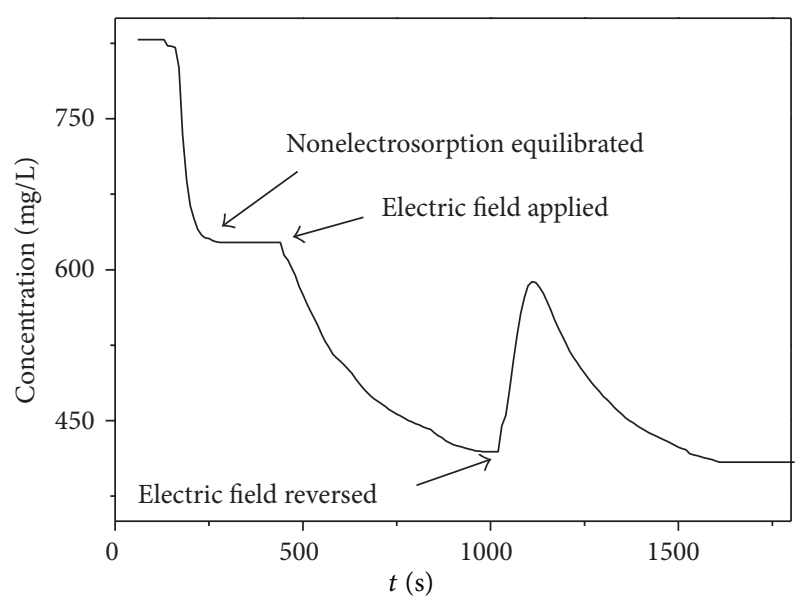

FIgURE 5: PAN-based ACFs' CDI dynamic adsorption curve.

$0.2 \mathrm{mmol} / \mathrm{g}$ of P10, and nearly $0.15 \mathrm{mmol} / \mathrm{g}$ of P7. P10 has a higher electrosorption capacity of CDI. This result shows ACFs with bigger pore width and pore volume and higher SSA (if not too high SSA); thus electrosorption capacity is higher.

3.3. CDI Configuration with Asymmetry Electrodes. We used two kinds of asymmetric electrodes in CDI described in the experiment. For convenience, when we connected the positive pole of power supply to the small-sized electrode, with the negative to the other, the voltage direction is regarded as forward voltage. On the other hand, when the positive pole power supply was connected to the big-sized electrode, the voltage direction is regarded as reverse voltage. It is interestingly found that asymmetric electrodes showed a different adsorption CDI capacity between forward voltage and reverse voltage. Under the condition of forward voltage, the electrodes adsorb more sodium chloride ions. Moreover, the electrosorption capacity increases with increasing the electrode ratio. The CDI data were compiled in Table 2. For the smaller anode electrode, it gave a smaller devisor and thus led to a higher electrosorption capacity. Porada et al. [21] had similar results with varied electrode ratio.

The reason for such difference could not be found in the EDL model [5]. In (2) of EDL model, $\sigma$ is electric charge density of the EDL, $\sigma_{0}$ is charge density around electrode surface in tight layer, $e^{\left(z e \varphi_{\delta}+\partial\right) / k T}$ is the Boltzmann factor, $N_{s}$ is the mole concentration of solution, $n_{0}$ is the positive or negative charge density in a far enough distance, $\varepsilon_{0}$ is vacuum permittivity, and $\varepsilon_{r}$ is relative permittivity.

$$
\sigma=\frac{\sigma_{0}}{1+1 / N_{s} e^{-\left(z e \varphi_{0}\right) / k T}}+\sqrt{8 n_{0} \varepsilon_{0} \varepsilon_{r} k T} \sinh \frac{z e \varphi_{\delta}}{2 k T} .
$$

The forward or reverse voltage condition did not change the factors in (2), which should lead to equal electrosorption capacity. The EDL theory was based on the hypothesis that electrodes are flat, without pores and microtopography. To explain the difference in electrosorption amount, the pore structure and microtopography of the electrode material

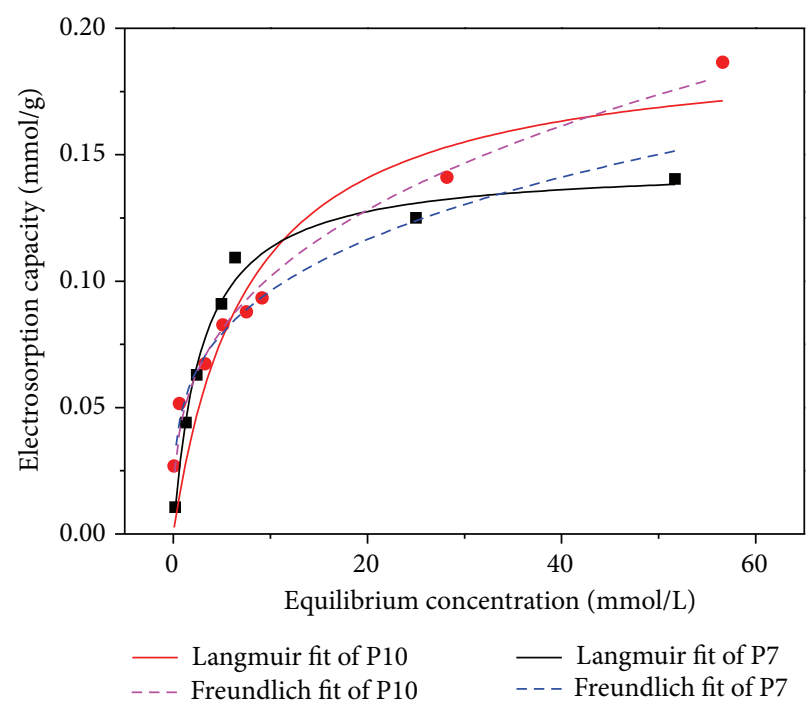

FIGURE 6: Electrosorption isotherms of $\mathrm{NaCl}$ and their fitting curves.

TABLE 2: Influence of asymmetric electrodes on CDI adsorption.

\begin{tabular}{lccccccc}
\hline Initial concentration of NaCl & \multicolumn{3}{c}{$100 \mathrm{mg} / \mathrm{L}$} & \multicolumn{4}{c}{$200 \mathrm{mg} / \mathrm{L}$} \\
\hline $\begin{array}{l}\text { Proportion of electrodes' size } \\
\begin{array}{l}\text { Electrosorption capacity of } \\
\text { reverse voltage (mg/g) }\end{array}\end{array}$ & $1: 1$ & $2: 1$ & $3: 1$ & $1: 1$ & $2: 1$ & $3: 1$ \\
$\begin{array}{l}\text { Electrosorption capacity of } \\
\text { forward voltage (mg/g) }\end{array}$ & 1.07 & 2.38 & 3.45 & 3.03 & 5.05 & 6.25 \\
\hline
\end{tabular}

have to be taken into account. In addition, the EDL overlap effect and the increase of inner-pore potential cannot be neglected. PAN-based ACFs are microporous materials; thus the EDL overlap effect and the inner-pore potential are fairly significant. These factors made ions with smaller hydrated ionic radius liable to enter into the micropores. The hydrated ionic radius of $\mathrm{Na}^{+}(3.58 \AA)$ is bigger than $\mathrm{Cl}^{-}$(3.32 $\AA$ ) [27], so $\mathrm{Cl}^{-}$can be adsorbed more easily. When the size of electrodes differed, smaller electrode reached adsorption equilibrium more quickly. To guarantee the electric neutrality of the outflow solution, the big electrode would not adsorb more ions even if it has more adsorption sites. Under the reverse voltage, $\mathrm{Na}^{+}$was adsorbed by small electrode, which was harder than $\mathrm{Cl}^{-}$under the forward voltage. Thereby, only a smaller number of $\mathrm{Na}^{+}$was adsorbed, which accordingly led to a low adsorption of chloride on the bigger electrode. Hence, the electrosorption capacity under reverse voltage was less than that under forward voltage.

To confirm that the difference in electrosorption capacity is caused by pore structure but not geometric changes, a comparison experiment was designed by using two same sized electrodes with different pore characteristics. One electrode was made of P7 with an average pore width of $1.9 \mathrm{~nm}$, and the other electrode was made of P10 with an average pore width of $2.0 \mathrm{~nm}$. When applying negative voltage on P10, the electrosorption amount was higher than the reversed condition. That is to say, when the larger pore material was 
used as negative electrode to adsorb $\mathrm{Na}^{+}$and the smaller pore material adsorbed $\mathrm{Cl}^{-}$, electrosorption capacity was higher. These results verify our explanation of the micromechanism adsorption.

\section{Conclusions}

PAN-based activated carbon fibers were used as CDI electrodes, which demonstrated a moderate electrosorption capacity. ACFs electrodes with higher specific surface area (as in the case of P10) and under higher solution concentration have higher electrosorption capacity. Because of the EDL overlap effect and inner-pore potential, ions with smaller hydrated ionic radius could be adsorbed in the electrode materials more easily. This could be proved by applying asymmetric electrodes in CDI experiments, which shows variation in electrosorption capacity between forward voltage and reverse voltage.

\section{Conflict of Interests}

The authors declare that they have no conflict of interests regarding the publication of this paper.

\section{Acknowledgments}

The authors are grateful for the financial support from the National Natural Science Foundation of China (Grant no. 51072091) and the cooperative Project JST-MOST (no. 2011DFA50430).

\section{References}

[1] C. J. Vörösmarty, P. Green, J. Salisbury, and R. B. Lammers, "Global water resources: vulnerability from climate change and population growth," Science, vol. 289, no. 5477, pp. 284-288, 2000.

[2] P. H. Gleick, "The changing water paradigm a look at twentyfirst century water resources development," Water International, vol. 25, no. 1, pp. 127-138, 2000.

[3] L. Wang, M. Wang, Z.-H. Huang et al., "Capacitive deionization of $\mathrm{NaCl}$ solutions using carbon nanotube sponge electrodes," Journal of Materials Chemistry, vol. 21, no. 45, pp. 18295-18299, 2011.

[4] M. Mossad and L. Zou, "A study of the capacitive deionisation performance under various operational conditions," Journal of Hazardous Materials, vol. 213-214, pp. 491-497, 2012.

[5] M. A. Anderson, A. L. Cudero, and J. Palma, "Capacitive deionization as an electrochemical means of saving energy and delivering clean water. Comparison to present desalination practices: will it compete?" Electrochimica Acta, vol. 55, no. 12, pp. 3845-3856, 2010.

[6] Y. Oren, "Capacitive deionization (CDI) for desalination and water treatment-past, present and future (a review)," Desalination, vol. 228, no. 1-3, pp. 10-29, 2008.

[7] J. Yang, L. Zou, and N. R. Choudhury, "Ion-selective carbon nanotube electrodes in capacitive deionisation," Electrochimica Acta, vol. 91, pp. 11-19, 2013.
[8] M. Inagaki, H. Konno, and O. Tanaike, "Carbon materials for electrochemical capacitors," Journal of Power Sources, vol. 195, no. 24, pp. 7880-7903, 2010.

[9] G. Wang, B. Qian, Q. Dong, J. Yang, Z. Zhao, and J. Qiu, "Highly mesoporous activated carbon electrode for capacitive deionization," Separation and Purification Technology, vol. 103, pp. 216-221, 2013.

[10] H. Li, L. Zou, L. Pan, and Z. Sun, "Novel graphene-like electrodes for capacitive deionization," Environmental Science and Technology, vol. 44, no. 22, pp. 8692-8697, 2010.

[11] P. S. Goh, A. F. Ismail, and B. C. Ng, "Carbon nanotubes for desalination: performance evaluation and current hurdles," Desalination, vol. 308, pp. 2-14, 2013.

[12] L. Pan, X. Wang, Y. Gao, Y. Zhang, Y. Chen, and Z. Sun, "Electrosorption of anions with carbon nanotube and nanofibre composite film electrodes," Desalination, vol. 244, no. 1-3, pp. 139-143, 2009.

[13] H. Li, T. Lu, L. Pan, Y. Zhang, and Z. Sun, "Electrosorption behavior of graphene in $\mathrm{NaCl}$ solutions," Journal of Materials Chemistry, vol. 19, no. 37, pp. 6773-6779, 2009.

[14] D. Zhang, X. Wen, L. Shi, T. Yan, and J. Zhang, "Enhanced capacitive deionization of graphene/mesoporous carbon composites," Nanoscale, vol. 4, pp. 5440-5446, 2012.

[15] Z. Wang, B. Doua, L. Zhengb, G. Zhangb, and Z. Liub, "Effective desalination by capacitive deionization with functional graphene nanocomposite as novel electrode material," Desalination, vol. 299, pp. 96-102, 2012.

[16] J. C. Farmer, D. V. Fix, G. V. Mack, R. W. Pekala, and J. F. Poco, "Capacitive deionization of $\mathrm{NaCI}$ and $\mathrm{NaNO}_{3}$ solutions with carbon aerogel electrodes," Journal of the Electrochemical Society, vol. 143, no. 1, pp. 159-169, 1996.

[17] K.-L. Yang, T.-Y. Ying, S. Yiacoumi, C. Tsouris, and E. S. Vittoratos, "Electrosorption of ions from aqueous solutions by carbon aerogel: an electrical double-layer model," Langmuir, vol. 17, no. 6, pp. 1961-1969, 2001.

[18] G. Wang, C. Pan, L. Wang et al., "Activated carbon nanofiber webs made by electrospinning for capacitive deionization," Electrochimica Acta, vol. 69, pp. 65-70, 2012.

[19] M.-W. Ryoo and G. Seo, "Improvement in capacitive deionization function of activated carbon cloth by titania modification," Water Research, vol. 37, no. 7, pp. 1527-1534, 2003.

[20] L. Wang, Z.-H. Huanga, M. Yueb, M. Lia, M. Wanga, and F. Kanga, "Preparation of flexible phenolic resin-based porous carbon fabrics by electrospinning," Chemical Engineering Journal, vol. 218, pp. 232-237, 2013.

[21] S. Porada, M. Bryjak, A. van der Wal, and P. M. Biesheuvel, "Effect of electrode thickness variation on operation of capacitive deionization," Electrochimica Acta, vol. 75, pp. 148-156, 2012.

[22] T.-H. Ko, P. Chiranairadul, and C.-H. Lin, "The influence of continuous stabilization on the properties of stabilized fibers and the final activated carbon fibers. Part I," Polymer Engineering \& Science, vol. 31, pp. 1618-1626, 1991.

[23] T.-H. Ko and C.-H. Li, "Influence of pre-carbonization on the properties of PAN-based carbon fibers developed by twostage continuous carbonization and air oxidation," Polymer Composites, vol. 16, no. 3, pp. 224-232, 1995.

[24] Z.-H. Huang, M. Wang, L. Wang, and F. Kang, "Relation between the charge efficiency of activated carbon fiber and its desalination performance," Langmuir, vol. 28, no. 11, pp. 50795084, 2012. 
[25] Z. Aksu, "Determination of the equilibrium, kinetic and thermodynamic parameters of the batch biosorption of nickel(II) ions onto Chlorella vulgaris," Process Biochemistry, vol. 38, no. 1, pp. 89-99, 2002.

[26] B. Özkaya, "Adsorption and desorption of phenol on activated carbon and a comparison of isotherm models," Journal of Hazardous Materials, vol. 129, no. 1-3, pp. 158-163, 2006.

[27] E. R. Nightingale Jr., "Phenomenological theory of ion solvation. Effective radii of hydrated ions," Journal of Physical Chemistry, vol. 63, no. 9, pp. 1381-1387, 1959. 

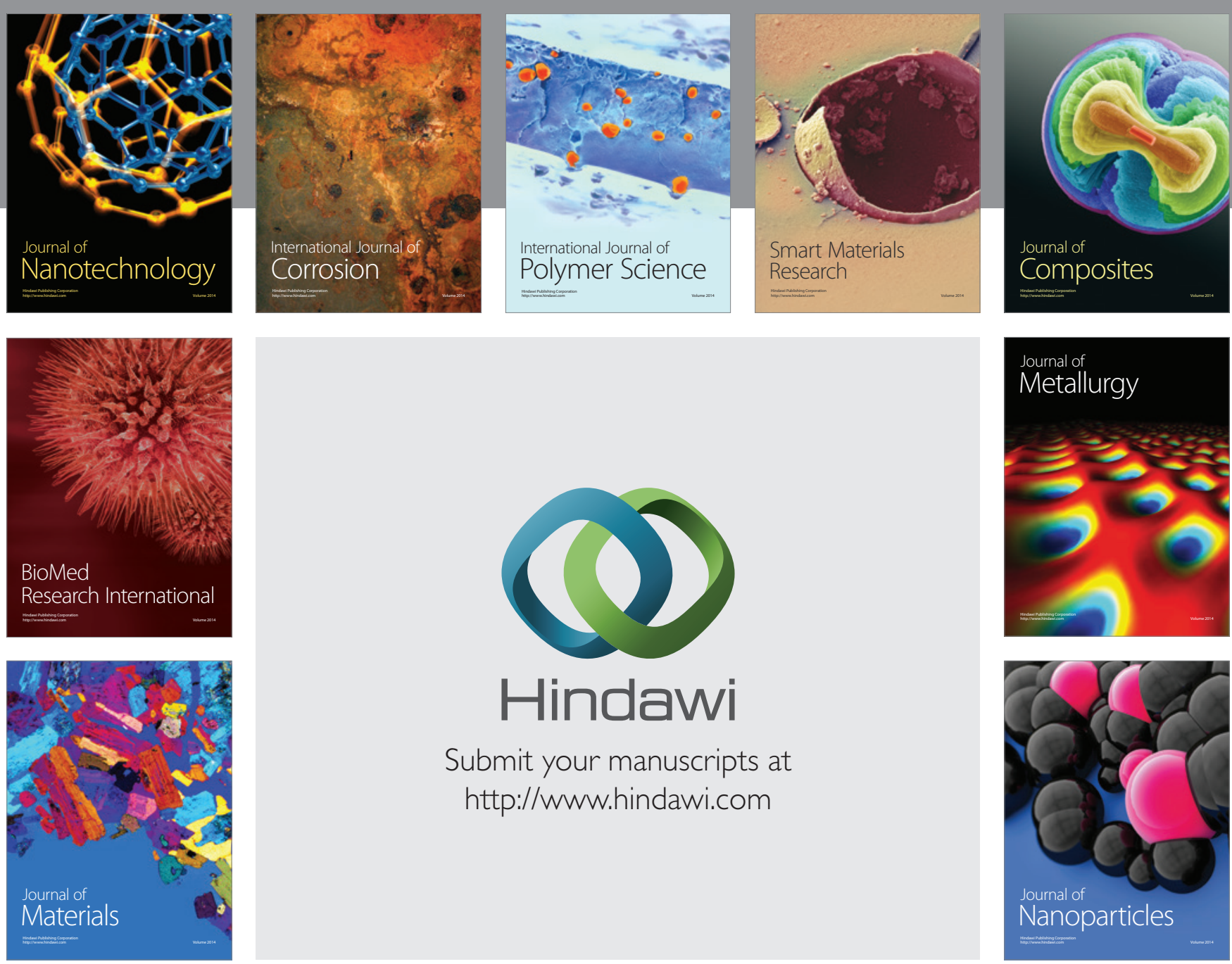

Submit your manuscripts at http://www.hindawi.com
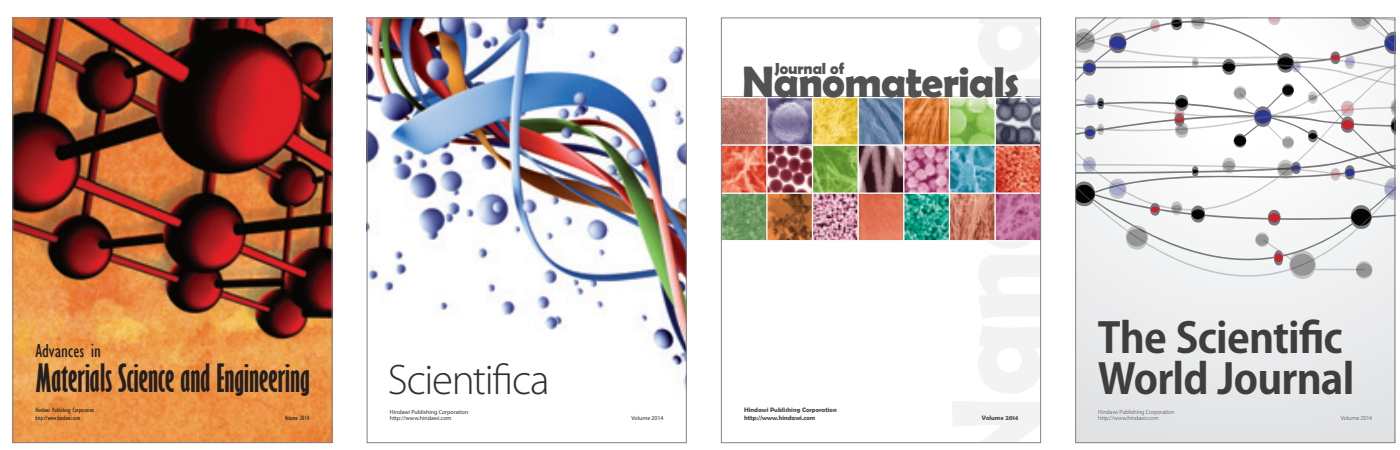

\section{The Scientific World Journal}
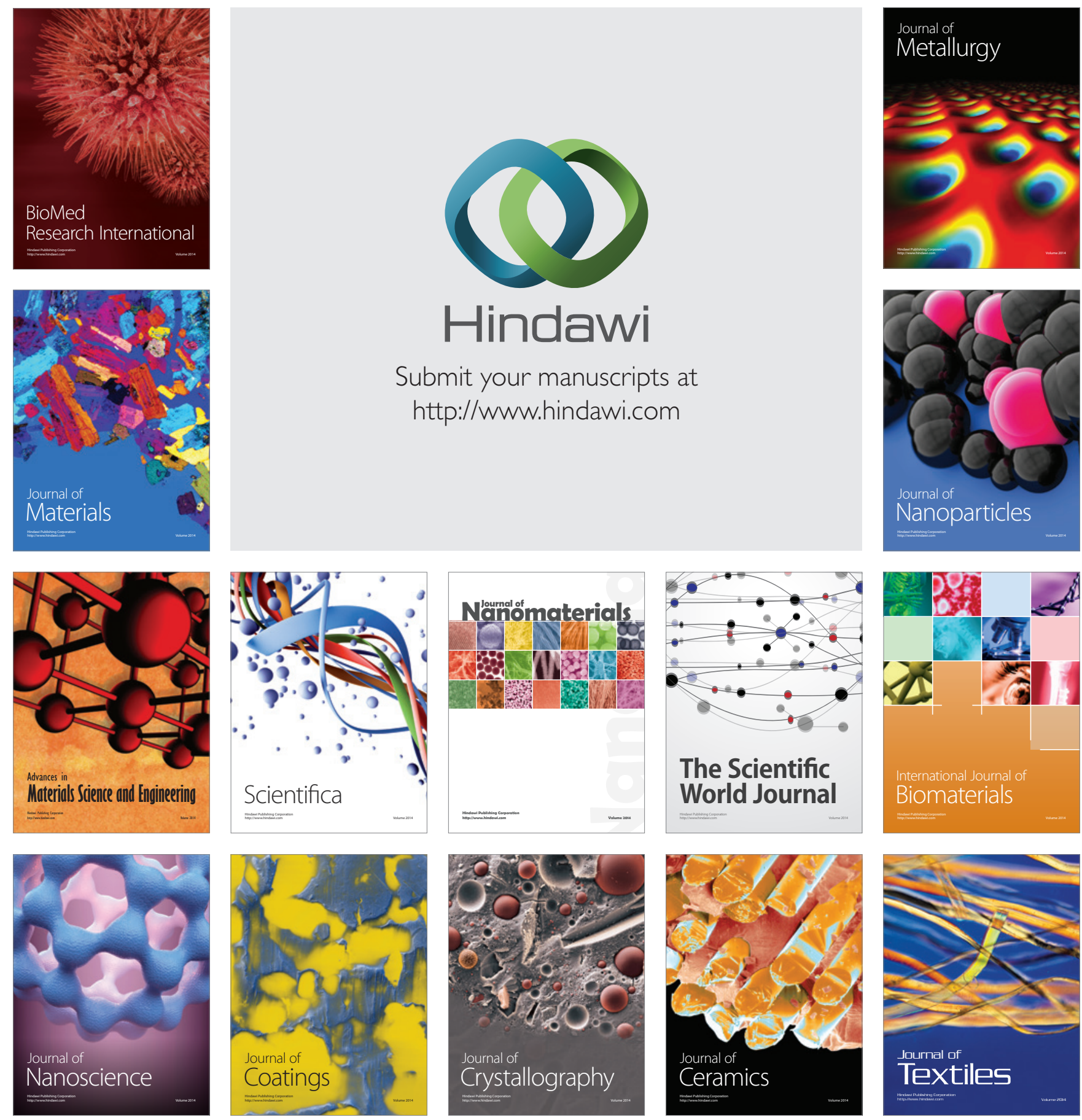